\title{
Rapid Restitution of the Lung Functions Following Short-Term Breath- Holding During Moderate Intensity Cycling Exercise
} \author{
Koichi Yoshioka ${ }^{3}$ and Gábor Pavlik ${ }^{1}$ \\ ${ }^{I}$ Department of Health and Sports Medicine, Semmelweis University, Hungary \\ ${ }^{2}$ Wellness Research Centre, Kokushikan University, Japan \\ ${ }^{3}$ Graduate School of Sport System, Kokushikan University, Japan
}

Hajnalka Németh $^{*}, 1$, Hatsue Saito ${ }^{2}$, Mayuko Kimura ${ }^{3}$, Izumi Kuboyama ${ }^{3}$, Susumu Ito ${ }^{3}$,

\begin{abstract}
Short periods of breath-holding $(\mathrm{BH})$ occur frequently during various kinds of sports activities. Increased minute oxygen uptake $\left(\mathrm{VO}_{2}\right)$, increased minute carbon dioxide output $\left(\mathrm{VCO}_{2}\right)$ and increased minute ventilation (VE) are some of the typical responses just after breaking the $\mathrm{BH}$ and resuming breathing and these parameters return to their steady levels over time. This study examined the properties of the restitution processes of lung functions after BH. Exercise tests were carried out with a bicycle ergometer for seven healthy male athletes and the ventilation activities and expired gases were measured with a breath-by-breath based aeromonitor. The respiratory responses to $25 \mathrm{~s} \mathrm{BH}$ were tested during continuous cycling at three exercise loads $(2 \mathrm{~W}, 22 \mathrm{~W}$ and $102 \mathrm{~W})$. A single exponential decay function with two parameters: initial amplitude (A) and time constant $(\tau)$, was fitted to the data of $\mathrm{VO}_{2}, \mathrm{VCO}_{2}$, VE, expiratory tidal volume (TVE) and respiratory rate (RR) after cessation of the BH. It was found that, except for RR, A was increased and $\tau$ was decreased with increasing the exercise intensity. The $\mathrm{A}$ of $\mathrm{VCO}_{2}$ was smaller and $\tau$ was longer than those of $\mathrm{VO}_{2}$ at all load intensities. The difference in the time courses of $\mathrm{VO}_{2}$ and $\mathrm{VCO}_{2}$ may be explained by the different buffer mechanisms of oxygen and carbon dioxide within the body.
\end{abstract}

Keywords: Breath-holding, restitution, lung functions, oxygen uptake, carbon dioxide output, exercise test.

\section{INTRODUCTION}

Breath-holding $(\mathrm{BH})$ occurs during various physical activities. $\mathrm{BH}$ is an important element, not only in water sport activities, but also in dry-land sport activities, such as athletics (sprint running, jumping, throwing), contact sports (judo, kendo) and weight lifting, and many studies have been conducted for examining various aspects of $\mathrm{BH}$ [1-12]. A distinctive phenomenon during $\mathrm{BH}$, which can be typically observed during face immersion with $\mathrm{BH}$, is the dive reflex, characterized by peripheral vasoconstriction (i.e. decreased blood flow to the working muscles and other organs) with concomitant bradycardia. [for review, see 13]. These responses may result in a decrease in the oxygen uptake by the organs. Thus, the aim of the dive reflex may be oxygen conservation during $\mathrm{BH}[14,15]$. Once the $\mathrm{BH}$ is over, the body may try to restore the usual balance of gases within the body. In the lungs the carbon dioxide accumulated during $\mathrm{BH}$ in the body may be removed by consecutive expirations and the consumed oxygen may be replenished by consecutive inspirations. In order to get rid of the oxygen deficit and carbon dioxide overload, various respiratory and circulatory functions may be transiently accelerated. Compared with the processes that occur during $\mathrm{BH}$, relatively little is known about the processes that occur

*Address correspondence to this author at the Department of Health and Sports Medicine, Semmelweis University, Alkotás u 44, H-1123 Budapest, Hungary; Tel/Fax: +81-92-583-7853; E-mails: hajnalka.nemeth@gmail.com, hajni@students.ihs.kyushu-u.ac.jp during this restitution phase after $\mathrm{BH}$. It would be interesting to compare the time courses of carbon dioxide output and oxygen uptake after $\mathrm{BH}$ under various degrees of exercise load and to investigate how their changes can be explained by characteristics of these gases and regulatory mechanisms of the body.

In this study we conducted an experiment using a cycleergometer with exercise loads of three levels (low, moderate and high), while monitoring various lung functions. We followed the time courses of minute oxygen uptake, minute carbon dioxide output and other lung functions after cessation of short-term $\mathrm{BH}$ and examined how they depended on the intensity of exercise load. In order to characterize these time courses, we fitted a single exponential decay curves to the lung functions and obtained the response amplitudes and the relaxation time constants.

\section{MATERIALS AND METHODOLOGY}

\section{Subjects}

Seven healthy male athletes took part in the study (two kendo athletes, two short distance swimmers, one soccer player, one sprinter, one volleyball player). None of them were members of national teams. All of them were nonsmokers. Their average age and SD was $24.0 \pm 2.9$ years, height $174.0 \pm 5.1 \mathrm{~cm}$, weight $65.5 \pm 10.6 \mathrm{~kg}$, and vital capacity $4.27 \pm 0.161$. None of the subjects had experience of underwater free diving. They gave their written consent to participate in the study. All the procedures were approved by 
Kokushikan University Ethics Committee for Research on Human Subjects.

\section{Study Protocol}

Preparation for the exercise test: The subjects were instructed to come to the laboratory at least $2 \mathrm{hr}$ after light meals, and without taking any caffeine-containing beverages. The room temperature was $21^{\circ} \mathrm{C}$. The subjects were wearing a T-shirt and shorts. On the first day, the vital capacity was measured using a spirometer (Autospiro AS-300, Minato Medical Science, Japan) while the subjects were in a sitting position and wearing a nose clip. Five min stretching was done before starting the exercise test.

The exercise test: Each subject performed one exercise test per day. The subjects mounted on a cycle-ergometer (Rehor 500P, Groningen, The Netherlands) and breathed into a coupler while wearing the nose clip. Chest electrocardiograms were continuously monitored with an electrocardiograph (BSM-7201, Nihon Kohden, Japan). Exercise began as soon as a stable resting heart rate (HR) was obtained. Arterial hemoglobin oxygen saturation $\left(\mathrm{SaO}_{2}\right)$ was measured on the middle finger of the right hand using a finger pulse oximeter. The ventilation activities and expired gases were analyzed with a breath-by-breath based aeromonitor (AE 300S, Minato Medical Science, Japan). The subjects were requested to maintain a pedal cadence of 60 70 revolutions per min during the exercise test. Respiratory responses to $\mathrm{BH}$ of each subject were recorded during continuous cycling at three exercise loads $(2 \mathrm{~W}, 22 \mathrm{~W}$ and
$102 \mathrm{~W}$ ) with one load on one day. The subjects were free to decide which intensity to select on which day. Warming-up of $2 \mathrm{~W}$ load was done in the first $7 \mathrm{~min}$. In the next 3 min the load was increased linearly to one of the exercise loads, which was then maintained for $35 \mathrm{~min}$. The subjects performed 4 sessions of $25 \mathrm{~s} \mathrm{BH}$, at the 20, 25, 30 and 35 min from the start of the test (Fig. 1).

The start and the end of the $\mathrm{BH}$ were issued by the experiment leader. The subjects were instructed not to hyperventilate before $\mathrm{BH}$. A BH started with a deep inspiration to a comfort level. Although we chose $25 \mathrm{~s}$ for the duration of $\mathrm{BH}$ as a tolerable period during exercise, the actual periods of $\mathrm{BH}$ were slightly shorter in average and differed at each loading: $24.4 \pm 2.2 \mathrm{~s}$ (mean $\pm \mathrm{SD}$ ) at $2 \mathrm{~W}$, $24.7 \pm 1.9 \mathrm{~s}$ at $22 \mathrm{~W}$, and $21.6 \pm 0.9 \mathrm{~s}$ at $102 \mathrm{~W}$. Responses to BHs shorter than $18 \mathrm{~s}$ or longer than $28 \mathrm{~s}$ were excluded from the study. (Two responses at 2 and $22 \mathrm{~W}$ were longer than $28 \mathrm{~s}$, respectively; four responses at $102 \mathrm{~W}$ were shorter than $18 \mathrm{~s}$ ).

\section{Data Analysis}

The analysis was divided into 2 steps: determination of the individual steady-state (SS) levels and determination of parameters of the restitution of lung functions to $\mathrm{BH}$ as relative values. In the latter, the initial amplitudes (A) of the restitution of the lung functions were first calculated, then single exponential decay curves were fitted on these responses and time constants $(\tau)$ of the restitution process were calculated.

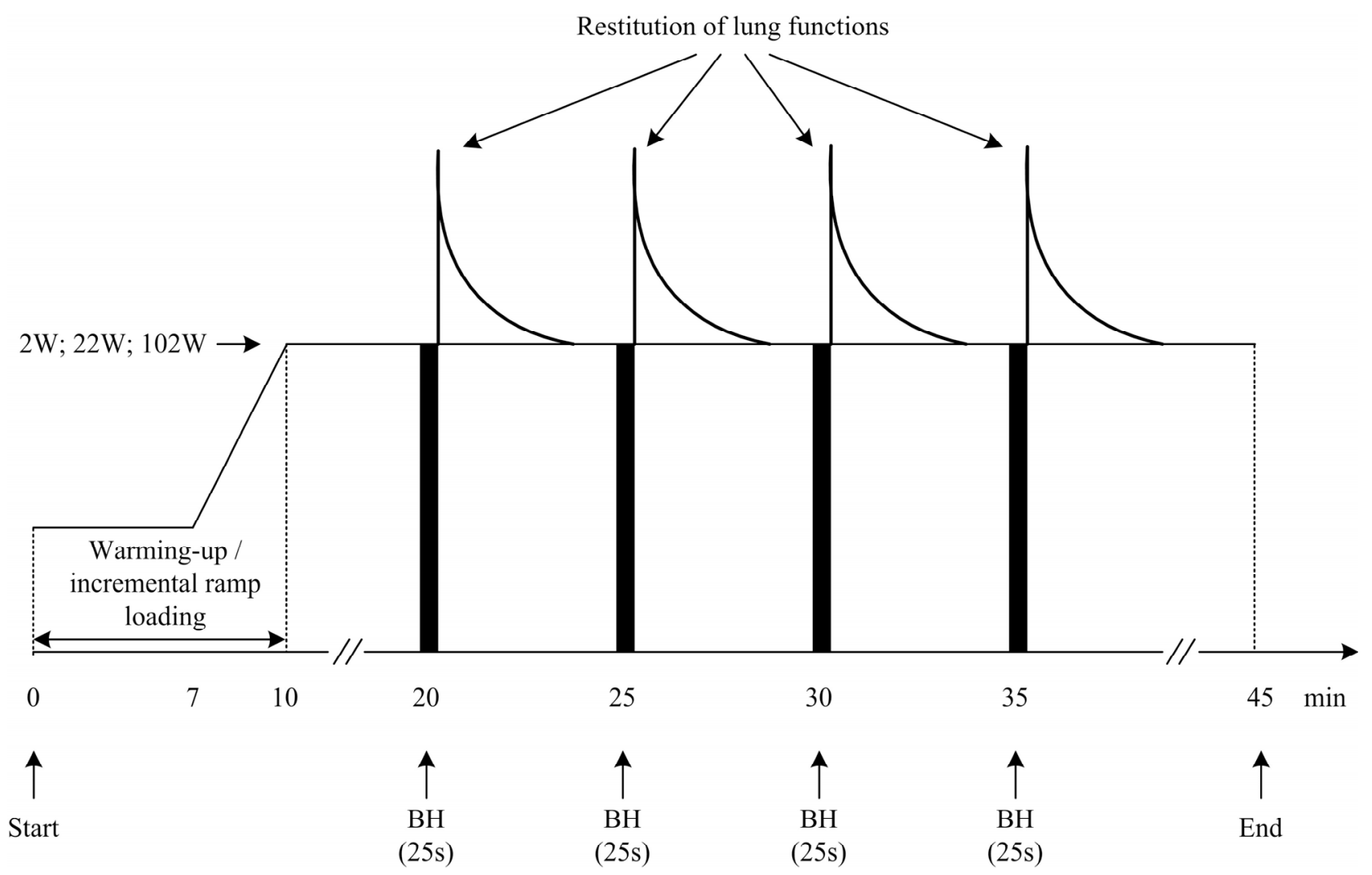

Fig. (1). Schematic illustration of the experimental protocol. Warming-up of $2 \mathrm{~W}$ load was done in the first $7 \mathrm{~min}$. In the next $3 \mathrm{~min}$ the load was increased linearly to one of the exercise loads, which was then maintained for $35 \mathrm{~min}$. The subjects performed $4 \mathrm{sessions}$ of $25 \mathrm{~s} \mathrm{BH}$, at the 20, 25, 30 and $35 \mathrm{~min}$ from the start of the test. 


\section{Determination of the Steady-State Levels}

The period just before the first $\mathrm{BH}$ was found to be appropriate for determining the steady state levels, because during the period the parameters examined were stable and variations were small. Thus, for each parameter examined, the average of the values of 30 consecutive expirations beginning at $15 \mathrm{~min}$ from the start of the test was calculated and used as the SS level. For each exercise load, the averages of the SS levels of various parameters for 7 subjects were calculated and are given in Table 1 (See Table 1 under Results).

\section{Determination of the Restitution Process of the Lung Functions}

Of the lung functions examined, the following five functions were selected for analyzing the restitution processes from $\mathrm{BH}$ : the minute oxygen uptake $\left(\mathrm{VO}_{2}\right)$, minute carbon dioxide output $\left(\mathrm{VCO}_{2}\right)$, expiratory tidal volume (TVE), respiratory rate (RR), minute ventilation (VE).

In each subject and each exercise load, the values of each lung function were first normalized by dividing them by the corresponding SS level. Then the normalized responses of 4 sessions to $\mathrm{BHs}$ were pooled by setting the time points of first breaths after the ends of $\mathrm{BH}$ as time zero and finally the responses of 7 subjects were pooled.

To obtain smoothed, averaged times courses of the data sets, a local quadratic polynomial regression model with Gaussian kernel was applied. This is a weighted average method with superior properties to simple moving average [16]. The value of the bandwidth was determined by AICc [17]. A single exponential model given below was also fitted to the data with a non-linear least squares method.

$$
y(t)=A \times e^{-\frac{t}{\tau}}+1+\text { error }
$$

where $y(t)$ is the value of a normalized response function at time $\mathrm{t}$; $\mathrm{A}$ is the initial amplitude and $\tau$ is the time constant of the exponential decay function. The curve fittings were performed using KyPlot 5.0 (KyensLab, Japan).

\section{RESULTS}

Table 1 gives the SS levels of 10 respiratory and cardiac function parameters at $2 \mathrm{~W}, 22 \mathrm{~W}$ and $102 \mathrm{~W}$ exercise loads. Means and SDs for 7 subjects are given.

$\dot{\mathrm{VO}} 2, \dot{\mathrm{VCO}}_{2}$ and $\mathrm{VE}$ changed markedly with the exercise load: they increased almost linearly with increasing the load and the values at $102 \mathrm{~W}$ were 3 to 4 fold larger than those at $2 \mathrm{~W}$. The values of TVE, RR and HR at $102 \mathrm{~W}$ were increased by about two-fold compared with those at $2 \mathrm{~W}$. By contrast, no appreciable changes were found in $\mathrm{ETO}_{2}$, $\mathrm{ETCO}_{2}, \mathrm{R}$, and $\mathrm{SaO}_{2}$ with changes in the exercise load.

Of the respiratory function parameters examined, those showed large changes with the exercise load, i.e., $\mathrm{VO}_{2}$, $\mathrm{VCO}_{2}, \mathrm{VE}$, TVE and RR, were selected and the changes after $\mathrm{BH}$ were examined. In Fig. (2), the time course of $\mathrm{VO}_{2}$ (normalized by SS levels) in the restitution period after $\mathrm{BH}$ for each exercise load is shown. The data of all subjects were pooled and plotted.
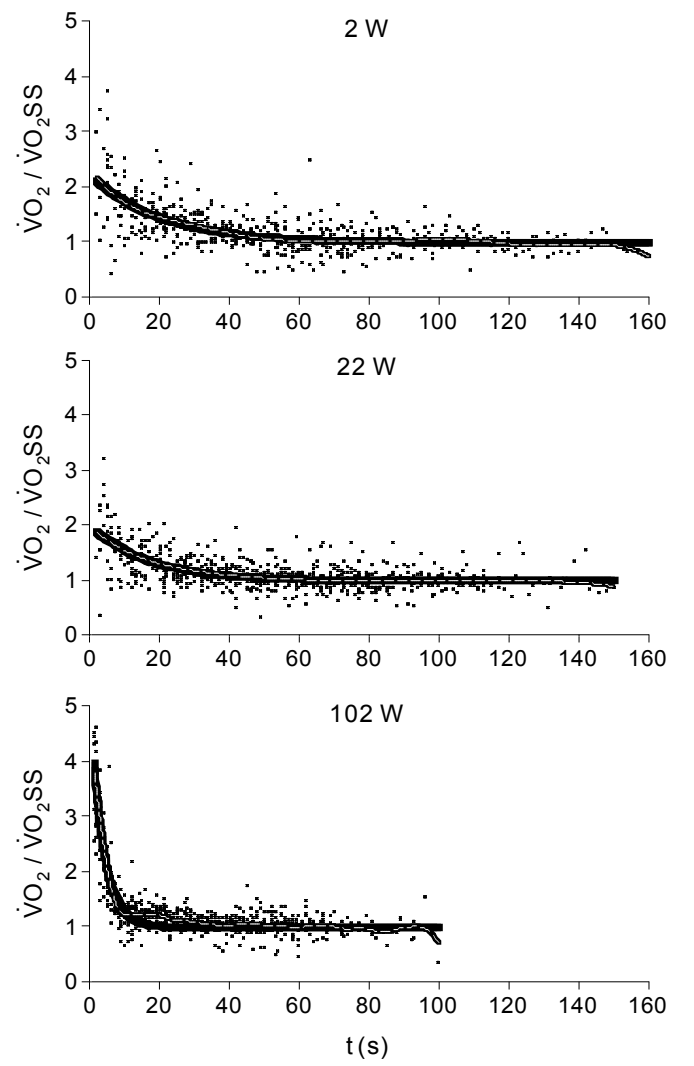

Fig. (2). Time courses of minute oxygen uptake relative to the steady-state level $\left(\mathrm{VO}_{2} / \mathrm{VO}_{2} \mathrm{SS}\right)$ in the restitution period after $\mathrm{BH}$. Each point represents the average of 4 sessions of an exercise trial of a subject and the data of all subjects examined are pooled and plotted. Open dashed line: smoothing curve and solid line: exponential fit.

Table 1. SS Levels of Various Parameters at $2 \mathrm{~W}, 22 \mathrm{~W}$ and $102 \mathrm{~W}$ Exercise Loads. Means \pm SDs for 7 subjects. The Parentheses for the Data at $22 \mathrm{~W}$ and $102 \mathrm{~W}$ are the Ratios of the Means Compared with the Corresponding Values at 2 W

\begin{tabular}{|c|c|c|c|c|c|c|c|c|c|c|}
\hline & $\begin{array}{c}\dot{V^{2} O_{2}} \\
(\mathrm{ml} / \mathrm{min})\end{array}$ & $\underset{(\mathrm{ml} / \mathrm{min})}{\mathrm{VCO}_{2}}$ & $\underset{(1 / \mathrm{min})}{\mathrm{VE}}$ & $\begin{array}{l}\text { TVE } \\
\text { (ml) }\end{array}$ & $\begin{array}{c}\text { RR } \\
(1 / \mathrm{min})\end{array}$ & $\begin{array}{c}\text { ETO }_{2} \\
(\%)\end{array}$ & $\begin{array}{c}\mathbf{E T C O}_{2} \\
(\%)\end{array}$ & $\mathbf{R}$ & $\begin{array}{c}\mathrm{SaO}_{2} \\
(\%)\end{array}$ & $\underset{(1 / \mathrm{min})}{\text { HR }}$ \\
\hline $2 \mathrm{~W}$ & $\begin{array}{l}384.2 \\
\pm 57.8\end{array}$ & $\begin{array}{l}312.0 \\
\pm 43.2\end{array}$ & $\begin{array}{l}11.6 \\
\pm 1.3\end{array}$ & $\begin{array}{l}746.3 \\
\pm 99.7\end{array}$ & $\begin{array}{l}17.4 \\
\pm 3.2\end{array}$ & $\begin{array}{l}14.5 \\
\pm 0.3\end{array}$ & $\begin{array}{c}5.5 \\
\pm 0.3\end{array}$ & $\begin{array}{c}0.80 \\
\pm 0.03\end{array}$ & $\begin{array}{l}97.6 \\
\pm 0.4\end{array}$ & $\begin{array}{c}71.8 \\
\pm 11.1\end{array}$ \\
\hline $22 \mathrm{~W}$ & $\begin{array}{l}562.4 \\
\pm 58.9 \\
(1.46)\end{array}$ & $\begin{array}{l}456.9 \\
\pm 46.8 \\
(1.46)\end{array}$ & $\begin{array}{c}15.4 \\
\pm 2.1 \\
(1.33)\end{array}$ & $\begin{array}{c}863.5 \\
\pm 148.9 \\
(1.16)\end{array}$ & $\begin{array}{c}19.0 \\
\pm 4.8 \\
(1.09)\end{array}$ & $\begin{array}{c}14.2 \\
\pm 0.3 \\
(0.98)\end{array}$ & $\begin{array}{c}5.7 \\
\pm 0.3 \\
(1.04)\end{array}$ & $\begin{array}{c}0.81 \\
\pm 0.03 \\
(1.01)\end{array}$ & $\begin{array}{c}97.4 \\
\pm 0.4 \\
(1.00)\end{array}$ & $\begin{array}{c}77.5 \\
\pm 9.7 \\
(1.08)\end{array}$ \\
\hline $102 \mathrm{~W}$ & $\begin{array}{l}1541.2 \\
\pm 66.8 \\
(4.01)\end{array}$ & $\begin{array}{l}1333.8 \\
\pm 88.8 \\
(4.28)\end{array}$ & $\begin{array}{c}38.1 \\
\pm 3.6 \\
(3.28)\end{array}$ & $\begin{array}{c}1570.8 \\
\pm 233.7 \\
(2.10)\end{array}$ & $\begin{array}{c}25.4 \\
\pm 5.1 \\
(1.46)\end{array}$ & $\begin{array}{c}14.1 \\
\pm 0.3 \\
(0.97)\end{array}$ & $\begin{array}{c}6.0 \\
\pm 0.2 \\
(1.09)\end{array}$ & $\begin{array}{c}0.87 \\
\pm 0.03 \\
(1.09)\end{array}$ & $\begin{array}{c}96.7 \\
\pm 0.5 \\
(0.99)\end{array}$ & $\begin{array}{c}133.7 \\
\pm 2.5 \\
(1.86)\end{array}$ \\
\hline
\end{tabular}


Although the data were highly variable, at $2 \mathrm{~W}$ exercise load, $\mathrm{VO}_{2}$ increased to about 2 -fold of the SS level on average immediately after $\mathrm{BH}$ and returned to the SS level in about $100 \mathrm{~s}$. The time course of $\mathrm{VO}_{2}$ at $22 \mathrm{~W}$ was similar to that at $2 \mathrm{~W}$, whereas at $102 \mathrm{~W}$, the initial rise was much larger and the decay to the SS level was more rapid.

In order to estimate the average time courses, the data were numerically smoothed and were plotted as dashed curves in Fig. (2). At $2 \mathrm{~W}$ and $22 \mathrm{~W}$, the curves were very smoothly and monotonically decreasing. At $102 \mathrm{~W}$, after the initial steep decline the smoothed curved showed a small "hump" in the period about 10 to $30 \mathrm{~s}$ after cessation of BH.

A single exponential model was fitted to the data of $\mathrm{VO}_{2}$ and is shown as solid curves in Fig. (2). Except for the period of the hump at $102 \mathrm{~W}$, the exponential fits were very close to the smoothed curves. The amplitudes (A) of the exponential model at each exercise load are given in Table $\mathbf{2}$ and the time constants $(\tau)$ in Table $\mathbf{3}$.

Table 2. Amplitudes (A) of Restitution Processes of 5 Lung Functions at $2 \mathrm{~W}, 22 \mathrm{~W}$ and $102 \mathrm{~W}$ Exercise Loads. A Single Exponential Decay Curve was Fitted to Pooled 20 Restitution Responses at 2 W; 23 Responses at $22 \mathrm{~W}$; and 22 Responses at $102 \mathrm{~W}$

\begin{tabular}{|c|c|c|c|}
\hline & $\mathbf{2 ~ W}$ & $\mathbf{2 2} \mathbf{~}$ & $\mathbf{1 0 2} \mathbf{~ W}$ \\
\hline \hline$\dot{\mathrm{VO}_{2}}$ & 1.22 & 0.99 & 3.91 \\
\hline $\mathrm{VCO}_{2}$ & 0.77 & 0.70 & 1.69 \\
\hline $\mathrm{TVE}$ & 0.59 & 0.71 & 0.56 \\
\hline $\mathrm{RR}$ & -0.20 & -0.17 & 0.49 \\
\hline $\mathrm{VE}$ & 0.39 & 0.37 & 1.25 \\
\hline
\end{tabular}

Table 3. Time Constant ( $\tau$ ) of Restitution Processes of 5 Lung Functions at $2 \mathrm{~W}, 22 \mathrm{~W}$ and $102 \mathrm{~W}$ Exercise Loads. A Single Exponential Decay Curve was Fitted to Pooled 20 Restitution Responses at 2 W; 23 Responses at $22 \mathrm{~W}$; and 22 Responses at $102 \mathrm{~W}$

\begin{tabular}{|c|c|c|c|}
\hline & $\mathbf{2 ~ W}$ & $\mathbf{2 2} \mathbf{~}$ & $\mathbf{1 0 2} \mathbf{~ W}$ \\
\hline \hline$\dot{\mathrm{VO}_{2}}$ & 19.7 & 16.6 & 3.7 \\
\hline $\mathrm{VCO}_{2}$ & 35.2 & 27.6 & 7.2 \\
\hline $\mathrm{TVE}$ & 23.0 & 21.5 & 8.4 \\
\hline $\mathrm{RR}$ & 10.0 & 15.4 & 31.6 \\
\hline $\mathrm{VE}$ & 47.9 & 36.6 & 13.9 \\
\hline
\end{tabular}

The changes in $\mathrm{VCO}_{2}$ in the restitution period are shown in Fig. (3).

The time courses at $2 \mathrm{~W}$ and $22 \mathrm{~W}$ were similar to those of $\mathrm{VO}_{2}$ and the exponential fits were very close to the smoothed curves. At $102 \mathrm{~W}$, the initial rise at the start of rebreathing was less pronounced than $\mathrm{VO}_{2}$ but the difference between the smoothed curve and exponential fit was large within the $10 \mathrm{~s}$ of the initial period. As in $\mathrm{VO}_{2}$, presence of a small hump was suggested by the smoothed curve in the period of about 10 to $30 \mathrm{~s}$ after cessation of $\mathrm{BH}$.
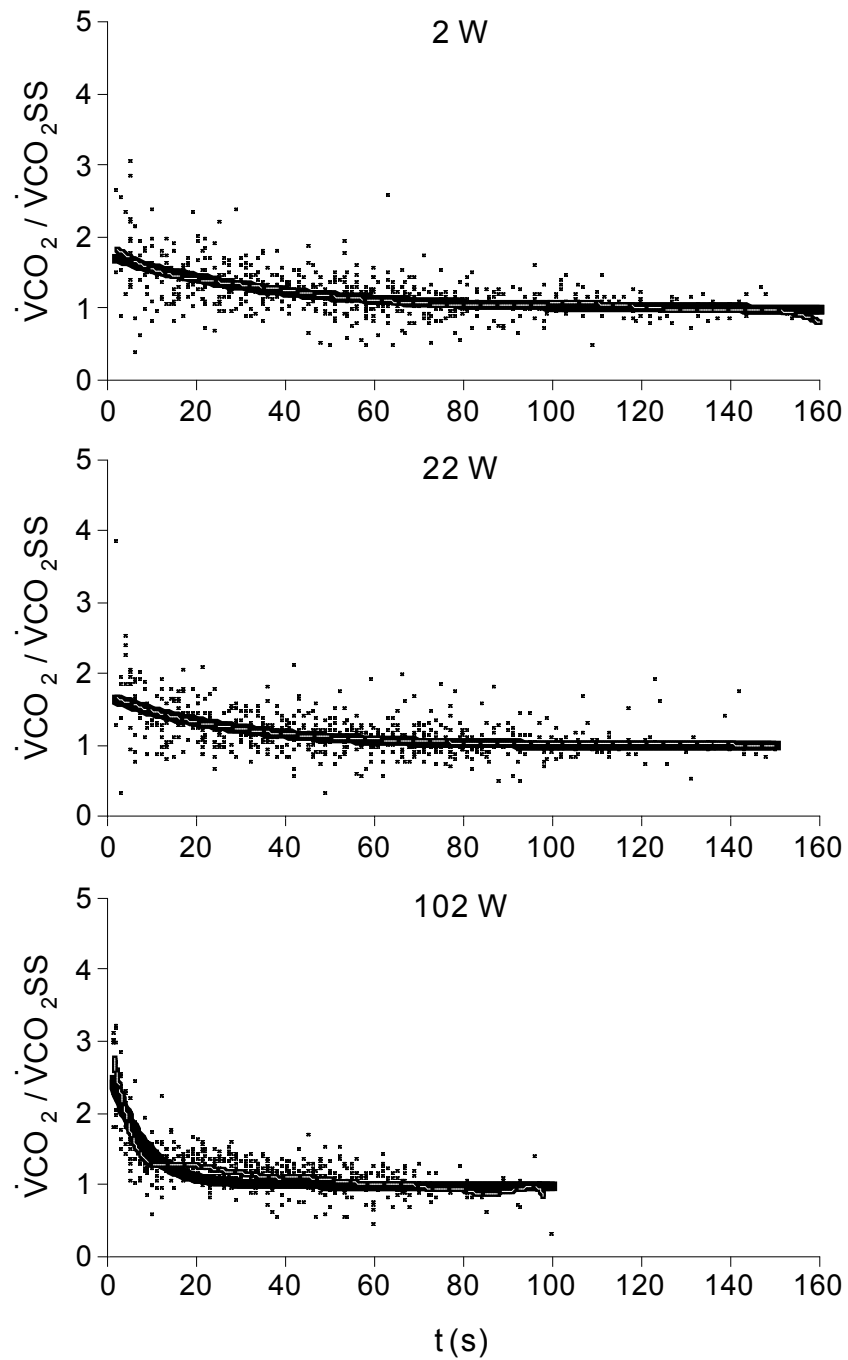

Fig. (3). Time courses of minute carbon dioxide output relative to the steady-state level $\left(\mathrm{VCO}_{2} / \mathrm{VCO}_{2} \mathrm{SS}\right)$ in the restitution period after BH. Other details are the same as in Fig. (2).

Fig. (4) gives the changes in TVE in the restitution period.

The time course at each exercise load was similar to $\mathrm{VO}_{2}$ and $\mathrm{VCO}_{2}$ and the smoothed curves and exponential fits were very close at all exercise loads.

In Fig. (5), the changes in RR are shown.

At $2 \mathrm{~W}$ and $22 \mathrm{~W}$, no initial rise was observed and the values in the initial $50 \mathrm{~s}$ were slightly lower than the SS levels. This tendency was apparent in the smoothed curves and exponential fits and reflected in the negative values of the amplitudes (A) in Table 2.

As shown in Fig. (6), the time courses of VE reflected those of TVE and RR, since it is given as the product of them.

At $102 \mathrm{~W}$, a slight deviation from the exponential model was apparent in the initial period as in RR.

\section{DISCUSSION}

In this study, we investigated the restitution processes of various lung functions to short-term breath-holding during exercise. To our knowledge, this may be the first study to 
examine the exercise intensity dependency of the rapidity in restitutions of lung functions to $\mathrm{BH}$ during dynamic leg exercise.

As given in Table 1, incrẹasing the exercise load resulted in marked increases of $\mathrm{VO}_{2}, \mathrm{VCO}_{2}$ and concomitant increases in respiratory and cardiac functions (VE, TVE and $\mathrm{RR}$ and HR). The fact that the even highest load (102 W) did not cause any appreciable changes in $\mathrm{ETO}_{2}, \mathrm{ETCO}_{2}, \mathrm{R}$, and $\mathrm{SaO}_{2}$ suggests that increased oxygen consumption and carbon oxide production due to increased exercise load up to this level were well compensated by regulatory mechanisms of the body.
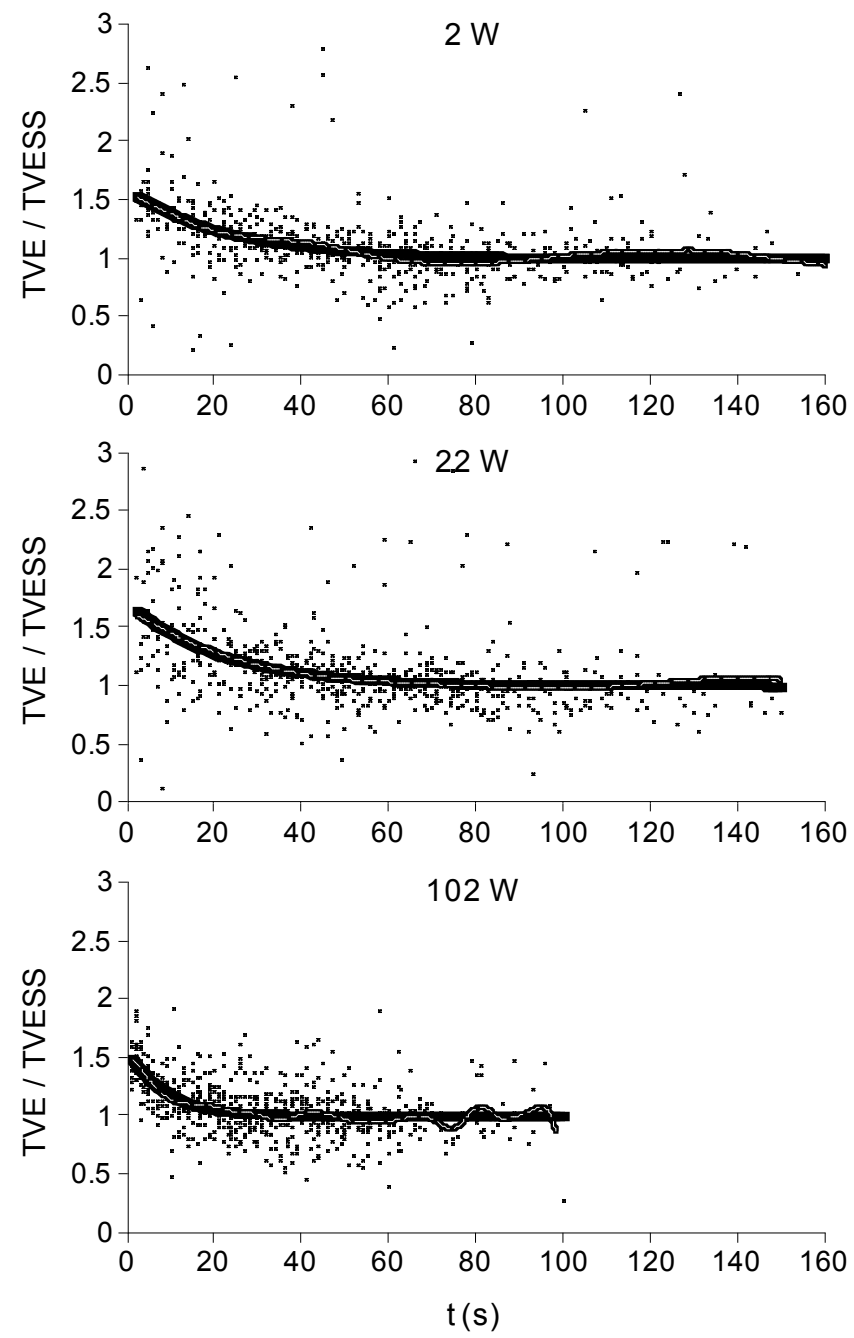

Fig. (4). Time courses of expiratory tidal volume relative to the steady-state level (TVE/TVESS) in the restitution period after BH. Other details are the same as in Fig. (2).

After cessation of $25 \mathrm{~s} \mathrm{BH}$, the values of $\mathrm{VO}_{2}$ and $\mathrm{VCO}_{2}$ rose promptly and then declined to the steady-state levels (Figs. 2, 3). Because they were considerably variable, a smoothing method was applied to the data. For both $\mathrm{VO}_{2}$ and $\mathrm{VCO}_{2}$, it gave very smooth and monotonically decreasing curves at low and moderate exercise loads, whereas at $102 \mathrm{~W}$, small humps following steep initial rises were apparent.

In order to obtain numerical characteristics of the restitution processes of lung functions, a single exponential model was fitted to the data and the initial amplitudes and time constants were estimated. For $\mathrm{VO}_{2}$, except for the period of the hump at $102 \mathrm{~W}$, the exponential fits were very close to the smoothed curves, suggesting that the single exponential model can sufficiently explain the restitution process of $\mathrm{VO}_{2}$. Similar results were obtained for $\mathrm{VCO}_{2}$, except that at $102 \mathrm{~W}$, the discrepancy between the smoothed curve and exponential fit was large in the initial period. Thus, except for this initial phase of $\mathrm{VCO}_{2}$ and the periods of the humps for $\mathrm{VO}_{2}$ and $\mathrm{VCO}_{2}$ at $102 \mathrm{~W}$, reasonable fitness of this model was obtained to the restitution data.
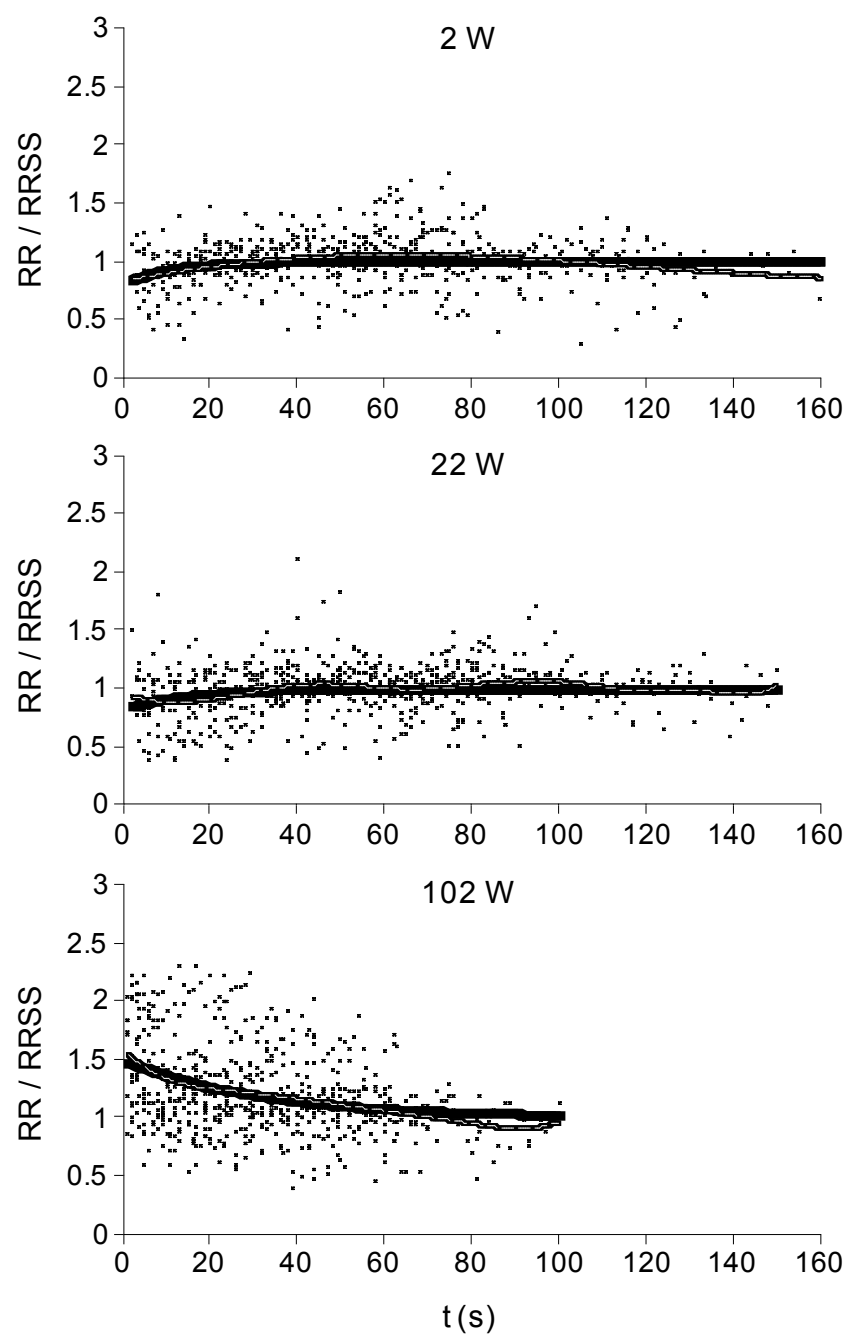

Fig. (5). Time courses of respiratory rate relative to the steady-state level (RR/RRSS) in the restitution period after BH. Other details are the same as in Fig. (2).

Increasing the exercise load may cause more intense oxygen deficit and carbon dioxide overload during $\mathrm{BH}$ and this may be reflected in the larger initial amplitudes of $\mathrm{VO}_{2}$ and $\mathrm{VCO}_{2}$ by increasing the load (Table 2). Interestingly, the time constants became smaller with the increase in the load (Table 3), suggesting that the regulatory mechanisms to restore usual balance of gases within the body were accelerated with the increase in the load. Accordingly, transient increases in respiratory functions, i.e., TVE, RR and VE after BH were observed (Figs. 4-6), but there were differences in the load intensity dependency among the three functions. Thus, in TVE, the initial increases were observed but not changed by increasing the load, with an increase in 
the decay at $102 \mathrm{~W}$; in RR the initial increase was observed only at $102 \mathrm{~W}$. Since VE is given as the product of TVE and $\mathrm{RR}$, it can be seen that the initial increases at $2 \mathrm{~W}$ and $22 \mathrm{~W}$ were due to those in TVE and those of both TVE and RR contributed to the increase at $102 \mathrm{~W}$. Another factor that may also contribute to the accelerated recovery of $\mathrm{O}_{2}$ and $\mathrm{CO}_{2}$ levels with the load intensity after $\mathrm{BH}$, is circulatory regulatory mechanisms. The relative contributions of respiratory and circulatory mechanisms remain to be clarified.
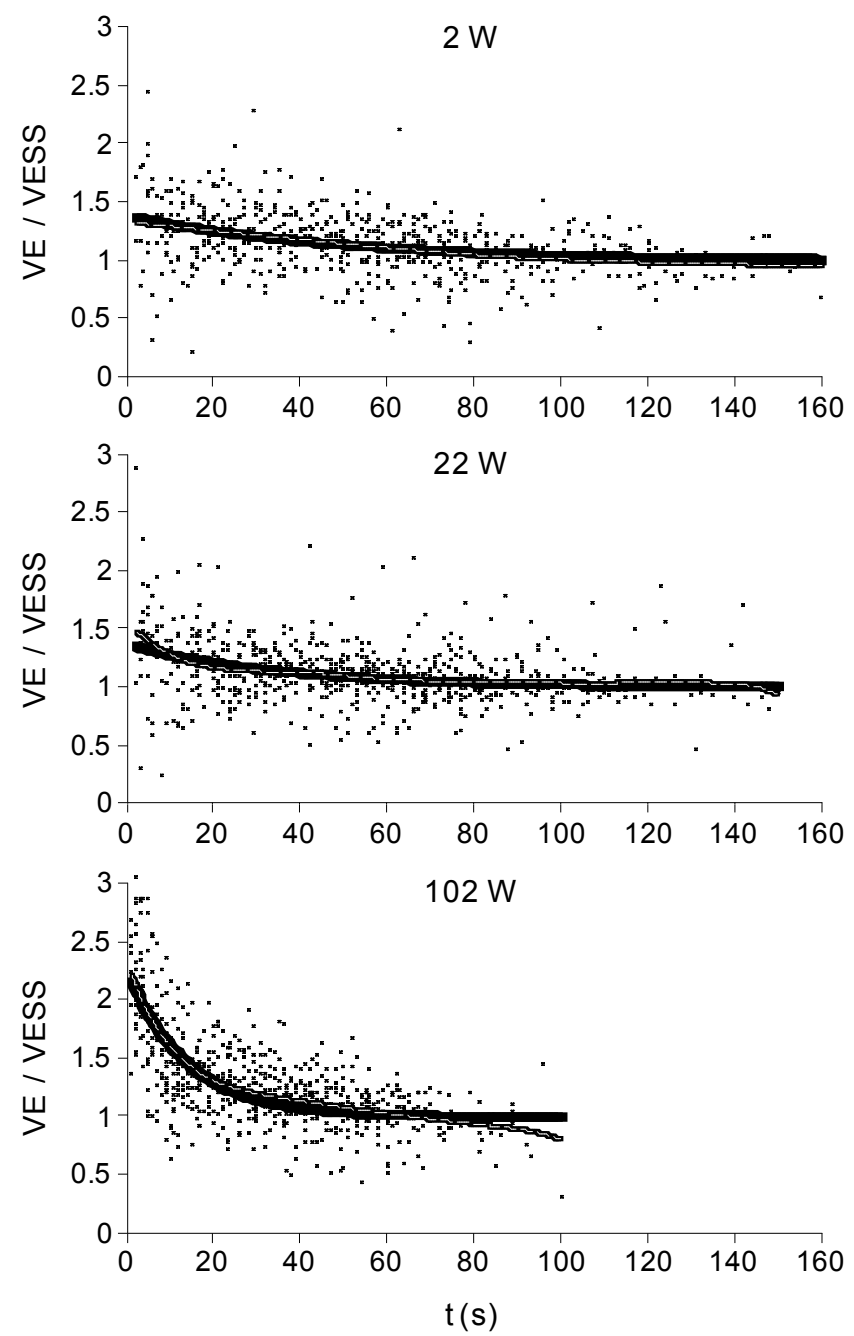

Fig. (6). Time courses of minute ventilation relative to the steadystate level (VE/VESS) in the restitution period after BH. Other details are the same as in Fig. (2).

Although the overall time courses of $\mathrm{VO}_{2}$ and $\mathrm{VCO}_{2}$ after $\mathrm{BH}$ were similar, they were not identical: the initial amplitudes of $\mathrm{VCO}_{2}$ were.smaller and the time constants were longer than those of $\mathrm{VO}_{2}$ (Tables 2 and 3 ) at. all load intensities. The difference in the time courses of $\mathrm{VO}_{2}$ and $\mathrm{VCO}_{2}$ may be explained by the different buffer mechanisms of oxygen and carbon dioxide within the body. The chemical reaction kinetics for $\mathrm{CO}_{2}$ is complex. $\mathrm{CO}_{2}$ is produced in the peripheral tissues and is buffered in the interstitial space and in the blood. During $\mathrm{BH}, \mathrm{CO}_{2}$ may accumulate in these compartments and take time for the blood to transport it to the lungs $[10,18,19]$. This may introduce a secondary, slow component to the $\mathrm{VCO}_{2}$ recovery, thus leading to a longer recovery time. The amount of oxygen deficit, on the other hand, may be much less than the amount of carbon dioxide overload. In order to restore the steady-state level of $\mathrm{VO}_{2}$, it may be sufficient to restore the usual balance inside the lungs. The changes of arterial hemoglobin oxygen saturation $\left(\mathrm{SaO}_{2}\right)$ during the $\mathrm{BH}$ could slow down the restitution of $\mathrm{VO}_{2}$, introducing a slow component, but in this study the duration of $\mathrm{BH}$ was rather short and the steady level of $\mathrm{SaO}_{2}$ did not change with the load intensity. Therefore, the amount of $\mathrm{SaO}_{2}$ decrease presumably did not reach the level where it could have affected the $\mathrm{O}_{2}$ restitution.

\section{CONCLUSION}

This study showed that increasing the exercise intensity led to faster restitution of $\mathrm{VO}_{2}$ and $\mathrm{VCO}_{2}$ in response to short-term $\mathrm{BH}$ during a constant load cycling exercise. Further studies are requited to elucidate the respiratory and circulatory mechanisms that contributed to the accelerated recovery of respiratory gases. It would also be worthwhile to investigate the characteristics of the restitution of the lung functions to $\mathrm{BH}$ in athletes at various fitness levels and in various sports.

\section{ACKNOWLEDGEMENTS}

We greatly appreciate the help and advice of Prof. Migita $\mathrm{T}$ (Kurume University) and Prof. Kumagai S, (Kyushu University) regarding the data interpretation.

\section{AUTHORS`CONTRIBUTION}

$\mathrm{NH}$ : study design, data collection, data analysis, data interpretation, literature search.

SH: study design, data collection, data analysis, data interpretation.

KM: study design, data collection, data analysis.

$\mathrm{KI}$ : data interpretation.

IS: study design, data interpretation.

YK: data analysis, data interpretation.

PG: data interpretation.

\section{ABBREVIATIONS}

$$
\begin{aligned}
& \mathrm{BH} \quad=\text { Breath-holding } \\
& \text { SS } \quad=\text { Steady-state } \\
& \tau \quad=\text { Time constant. } \\
& \text { A } \quad=\text { Amplitude } \\
& \dot{\mathrm{VO}}_{2} \quad=\text { Minute oxygen uptake } \\
& \dot{\mathrm{VCO}}_{2} \quad=\text { Minute carbon dioxide output } \\
& \text { TVE } \quad=\text { Expiratory tidal volume } \\
& \text { RR = Respiratory rate } \\
& \mathrm{VE} \quad=\text { Minute ventilation } \\
& \dot{\mathrm{VO}_{2}} / \mathrm{VO}_{2} \mathrm{SS}=\text { Minute oxygen uptake relative to the } \\
& \text { steady-state level } \\
& \dot{\mathrm{VCO}_{2}} / \dot{\mathrm{V} C O}{ }_{2} \mathrm{SS}=\text { Minute carbon dioxide output relative to }
\end{aligned}
$$



TVE/TVESS = Expiratory tidal volume relative to the steady-state level
$\mathrm{RR} / \mathrm{RRSS}=$ Respiratory rate relative to the steady- state level
$\mathrm{VE} / \mathrm{VESS} \quad=$ Minute ventilation relative to the steady- state level
$\mathrm{R}=$ Respiratory quotient
$\mathrm{ETO}_{2} \quad=$ End-tidal oxygen concentration
$\mathrm{ETCO}_{2} \quad=$ End-tidal carbon dioxide concentration
HR = Heart rate
$\mathrm{SaO}_{2} \quad=$ Arterial hemoglobin oxygen saturation

\section{REFERENCES}

[1] Ferretti G. Extreme human breath-hold diving. Eur J Appl Physiol 2001; 84: 254-71.

[2] Ashcroft F. Life under Pressure. Life at the extremes: the science of survival. London: Flamingo 2001; pp. 47-98.

[3] Hong SK, Rahn H. The diving women of Korea and Japan. Sci Am 1967; 216: 34-43.

[4] Dubois AB. Alveolar $\mathrm{CO}_{2}$ and $\mathrm{O}_{2}$ during breath holding, expiration, and inspiration. J Appl Physiol 1952; 5: 1-12.

[5] Hong SK, Lin YC, Lally DA, et al. Alveolar gas exchanges and cardiovascular functions during breath holding with air. J Appl Physiol 1971; 30: 540-7.

[6] Furedy JJ, Morrison JW, Heslegrave RJ, Arabian JM. Effects of water temperature on some noninvasively measured components of the human dive reflex: an experimental response-topography analysis. Psychophysiology 1983; 20: 569-78.

[7] Andersson J, Schagatay E. Arterial oxygen desaturation during apnea in humans. Undersea Hyperb Med 1998; 25: 21-5.
[8] Gan LM, Hägg U, Wandt B. A short period of apnoea causes a marked increase in coronary flow velocity: a transthoracic pulsed wave Doppler study. Clin Physiol Funct Imaging 2005; 25: 148-51.

[9] Lindholm P, Nordh J, Gennser M. The heart rate of breath-hold divers during static apnea: effects of competitive stress. Undersea Hyperb Med 2006; 33: 119-24.

[10] Hyde RW, Puv RJ, Raub WF, Forster RE. Rate of disappearance of labeled carbon dioxide from the lungs of humans during breath holding: a method for studing the dynamics of pulmonary $\mathrm{CO}_{2}$ exchange. J Clin Invest 1968; 47: 1535-52.

[11] Bjertnaes L, Hauge A, Kjekshus J, Søyland E. Cardiovascular responses to face immersion and apnea during steady state muscle exercise. A heart catheterization study on humans. Acta Physiol Scand 1984; 120: 605-12.

[12] Hoffmann U, Smerecnik M, Leyk D, Essfeld D. Cardiovascular responses to apnea during dynamic exercise. Int J Sports Med 2005; 26: 426-31.

[13] Hurwitz BE, Furedy JJ. The human dive reflex: an experimental, topographical and physiological analysis. Physiol Behav 1986; 36 : 287-94.

[14] Andersson JP, Linér MH, Rünow E, Schagatay EK. Diving response and arterial oxygen saturation during apnea and exercise in breath-hold divers. J Appl Physiol 2002; 93: 882-6.

[15] Lindholm P, Sundblad P, Linnarsson D. Oxygen-conserving effects of apnea in exercising men. J Appl Physiol 1999; 87: 2122-7.

[16] Loader CR. Local regression and likelihood. New York: Springer 1999.

[17] Hurvich CM, Simonoff JS. Smoothing parameter selection in nonparametric regression using an improved Akaike information criterion. J R Statist Soc B 1998; 60: 271-93.

[18] Farhi LE. Gas stores of the body. In: Fenn WO, Rahn H, Eds. Handbook of physiology: respiration. Washington, DC: American Physiological Society 1964; pp. 873-85.

[19] Linér MH. Cardiovascular and pulmonary responses to breath-hold diving in humans. Acta Physiol Scand Suppl 1994; 620: 1-32. 